\title{
Activation of Glycogen Synthase Kinase-3 Inhibits Long- Term Potentiation with Synapse-Associated Impairments
}

\author{
Ling-Qiang Zhu, ${ }^{1 *}$ Shao-Hui Wang, ${ }^{1 *}$ Dan Liu, ${ }^{1}$ Yang-Yang Yin, ${ }^{1}$ Qing Tian, ${ }^{1}$ Xiao-Chuan Wang, ${ }^{1}$ Qun Wang, ${ }^{1}$ \\ Jian-Guo Chen, ${ }^{2}$ and Jian-Zhi Wang ${ }^{1,2}$ \\ ${ }^{1}$ Department of Pathophysiology and ${ }^{2}$ Hubei Provincial Key Laboratory of Neurological Diseases, Tongji Medical College, Huazhong University of Science \\ and Technology, Wuhan 430030, People's Republic of China
}

\begin{abstract}
Activation of glycogen synthase kinase-3 (GSK-3) can cause memory deficits as seen in Alzheimer's disease, the most common ageassociated dementia, but the mechanism is not understood. Here, we found that activation of GSK-3 by wortmannin or transient overexpression of wild-type GSK- $3 \beta$ could suppress the induction of long-term potentiation (LTP) in rat hippocampus, whereas simultaneous inhibition of GSK-3 by lithium or SB216763 or transient expression of a dominant-negative GSK-3 $\beta$ mutant (dnGSK-3 $\beta$ ) preserved the LTP. After high-frequency stimulation (HFS), the presynaptic release of glutamate and the expression/clustering of synapsin I, a synaptic vesicle protein playing an important role in neurotransmitter release, decreased markedly after upregulation of GSK-3. In vitro studies further demonstrated that GSK-3 inhibited the expression of SynI independent of HFS. In postsynaptic level, the expression of PSD93 and NR2A/B proteins decreased significantly when GSK-3 was activated. The LTP-associated synapse impairments including less presynaptic active zone, thinner postsynaptic density, and broader synaptic cleft were also prominent in the hippocampal slices after HFS with activation of GSK-3. These synaptic impairments were attenuated when GSK-3 was simultaneously inhibited by LiCl or SB216763 or transient expression of dnGSK-3. We conclude that upregulation of GSK-3 impairs the synaptic plasticity both functionally and structurally, which may underlie the GSK-3-involved memory deficits.
\end{abstract}

Key words: glycogen synthase kinase-3; long-term potentiation; glutamate; synapse; synapsin I; postsynaptic density

\section{Introduction}

Glycogen synthase kinase-3 (GSK-3) is a protein kinase with diverse physiological functions in mediating intracellular signaling, regulating neuronal plasticity, gene expression, and cell survival (Grimes and Jope, 2001). It also plays an important role in Alzheimer's disease $(\mathrm{AD})$, the most common age-associated neurodegenerative disorder, characterized by formation of neurofibrillary tangles and senile plaques, as well as progressive memory loss (Ramsden et al., 2005). The major protein component of the tangles is the hyperphosphorylated microtubule-associated protein tau (Grundke-Iqbal et al., 1986a,b; Lee et al., 1991). Previous studies have demonstrated that upregulation of GSK-3 by conditional induction (Hernandez et al., 2002; Engel et al., 2006) in mice or by simultaneous inhibition of phosphatidyl inositol 3

Received April 21, 2007; revised Aug. 24, 2007; accepted Sept. 9, 2007.

This work was supported in part by the National Natural Science Foundation of China $(30400068,30430270$, and 30328007) and the National Science and Technology Committee of China (2006CB500703 and 2006AA02Z4A1). We thank Dr. L. H. Tsai at the Massachusetts Institute of Technology for her constructive suggestions and proofreading of this manuscript; Dr. J. R. Woodgett at the University of Toronto for the generous gifts of wild-type and dominantnegative GSK-3 plasmids; Dr. K. Marcelo at the Center for Experimental Therapeutics and Department of Pharmacology, University of Pennsylvania School of Medicine (Philadelphia, PA) for the gift of HA-pcDNA3.0 plasmid; Dr. H. Xu at Burnham Institute for Neuroscience for the N2a cell line; and Drs. K. Iqbal, I. Grundke-Iqbal, C. X. Gong, and F. Liu at New York State Institute for Basic Research for their technical support.

*L.-Q.Z. and S.-H.W. contributed equally to this work.

Correspondence should be addressed to Dr. Jian-Zhi Wang, Department of Pathophysiology, Institute of Neuroscience, Tongji Medical College, Huazhong University of Science and Technology, Wuhan 430030, People's Republic of China.E-mail:wangjz@mails.tjmu.edu.cn.

DOI:10.1523/JNEUROSCI.3321-07.2007

Copyright $\odot 2007$ Society for Neuroscience $\quad 0270-6474 / 07 / 2712211-10 \$ 15.00 / 0$ kinase and protein kinase C (Liu et al., 2003) in rats not only induces tau hyperphosphorylation, but also impairs spatial learning and memory. Moreover, several recent studies have shown that two types of reagents approved for the $\mathrm{AD}$ therapy, i.e., an inhibitor of acetylcholinesterase (Scarpini et al., 2003) and a blocker of NMDA receptor (Reisberg et al., 2003), can increase the inhibitory serine phosphorylation of GSK-3 in mouse brain and thus lead to the inhibition of the kinase (De Sarno et al., 2006). These lines of evidence suggest that activation of GSK-3 impairs learning and memory, whereas inhibition of GSK-3 reverses this effect. However, the mechanism by which GSK-3 regulates learning and memory is not understood.

Long-term potentiation (LTP) in hippocampus is recognized as the most plausible and the most intensively studied model for the cellular mechanisms of synaptic plasticity that may underlie memory function (Bliss and Lomo, 1973; Martin et al., 2000). Altered synaptic transmission and impaired LTP were shown in the transgenic mice bearing a familial AD mutant of amyloid precursor protein (Chapman et al., 1999; Larson et al., 1999). Additionally, spatial learning deficits were observed in a conditional mouse model overexpressing GSK-3 in the brain (Hernandez et al., 2002). GSK-3 is a major tau kinase playing a crucial role in AD-like hyperphosphorylation of tau (Engel et al., 2006; Plattner et al., 2006; Rockenstein et al., 2007), which is proposed to be a prelude to the formation of neurofibrillary tangles in the $\mathrm{AD}$ brains. An in vitro study also revealed that lithium, the seminal inhibitor of GSK-3 (Jope, 2003), could enhance LTP in dentate 
gyrus independent of neurogenesis (Son et al., 2003). Lithium was also shown to induce axonal remodeling and change the synaptic connectivity that was independent of inositol depletion and appeared to be mediated by GSK-3 (Lucas and Salinas, 1997; Lucas et al., 1998). A most recent study demonstrated that GSK-3 was inhibited during LTP, and it was activated during long-term depression (Peineau et al., 2007). Another recent study showed that conditional expression of GSK-3 in mouse brain inhibited LTP (Hooper et al., 2007). Until now, the possible molecular link between GSK-3 and LTP is still missing.

In the present study, we demonstrated in rat hippocampus that upregulation of GSK-3 inhibited the induction and maintenance of LTP, which is accompanied by prominent impairment of synapses. We propose that GSK-3 may play a key role in regulating synaptic plasticity, which in turn contributes to the learning/memory deficits in neurological disorders, including $\mathrm{AD}$.

\section{Materials and Methods}

Antibodies and plasmids. Rabbit monoclonal antibody $(\mathrm{mAb})$ against total GSK-3 $\beta$ (1:1000 for Western, 1:200 for immunohistochemistry) and rabbit polyclonal antibody $(\mathrm{pAb})$ against phosphorylated GSK-3 $\beta$ at Ser9 (1:1000 for Western, 1:200 for immunohistochemistry) were from Cell Signaling Technology (Beverly, MA); pAb against synapsin I ( 1:500 for Western blot, 1:1000 for immunofluorescence), pAb against PSD93 (3 $\mu \mathrm{g} / \mathrm{ml})$, NMDA receptor 1 (NMDAR 1) $(0.5 \mu \mathrm{g} / \mathrm{ml})$, NMDAR $2 \mathrm{~A} / \mathrm{B}(0.5 \mu \mathrm{g} / \mathrm{ml})$, and $\mathrm{mAb}$ against $\alpha$-tubulin $(1: 1000)$ were from Abcam (Cambridge, UK); pAb against PKA II $\alpha$ (1:1000) was from Santa Cruz Biotechnology (Santa Cruz, CA); and mAb against synaptophysin (1:1000) was from Sigma (St. Louis, MO). Neurobasal and B27 were from Invitrogen (Rockville, MD). Wild-type and dominantnegative GSK- $3 \beta$ plasmids were gifts from Dr. J. R. Woodgett at Toronto University (Toronto, Ontario, Canada). Hemagglutinin (HA)pcDNA3.0 plasmid was a gift from Dr. K. Marcelo at the University of Pennsylvania School of Medicine (Philadelphia, PA).

Animals. Wistar rats (grade II, male, weight 250-300 g, 4 months old) were purchased from the Experimental Animal Center of Tongji Medical College. All animal experiments were performed according to the "Policies on the Use of Animals and Humans in Neuroscience Research" revised and approved by the Society for Neuroscience in 1995. All rats were kept under standard laboratory conditions: $12 \mathrm{~h}$ light and $12 \mathrm{~h}$ dark; lights on at 6:00 A.M.; temperature: $22 \pm 2^{\circ} \mathrm{C}$; water and food ad libitum.

Brain surgery and electrophysiological recording. Rats were anesthetized by urethane $(1.2 \mathrm{~g} / \mathrm{kg})$ and placed on a Narishige (Tokyo, Japan) stereotaxic instrument (SR-6N). The body temperature of the rats was maintained at $\sim 37^{\circ} \mathrm{C}$ using a bath circulator. The skull was exposed, and a small hole was made at the appropriate coordinates to enable vertical penetration by the stimulating and recording electrodes. As shown in Figure $1 \mathrm{~A}$, the stimulating electrode made of a bipolar stainless steel was placed in the area of perforant path at coordinates of approximately anteroposterior (AP) -6.9 to -7.1 , mediolateral (ML) $\pm 4.4-4.6$, and dorsoventral (DV) -3.4 to -3.6 according to the rat brain atlas of Paxinos and Watson (1998); the recording electrode made of stainless-steel wires with $100 \mu \mathrm{m}$ diameter was placed in CA3 at coordinates of approx- imately $\mathrm{AP}-3.4$ to $-3.6, \mathrm{ML} \pm 3.4-3.6$, and $\mathrm{DV}-3.2$ to -3.4 ; the drug administration system was placed in CA3 at coordinates of AP -3.5 , ML +3.5, and DV -3.0. The GSK-3 modulators, wortmannin (Wort) or lithium chloride (Li) (Sigma) or SB216763 (SB; Tocris Bioscience, Bristol, UK), were infused $30 \mathrm{~min}$ before the recording. For the transient transfection of wild-type GSK-3 $\beta$ (wtGSK-3 $\beta$ ), or a dominant-negative mutant GSK-3 $\beta$ (dnGSK-3 $\beta$ ) or its pcDNA vector, Lipofectamine 2000 (Invitrogen) was used following the manufacturer's instructions, and the expression of the transfected genes was confirmed by immunostaining. Electrophysiological recording was performed as reported previously (Berger and Yeckel, 1991). Briefly, initial baseline responses were obtained by delivering a single pulse of stimulation once every $10 \mathrm{~s}$. For each recording experiment, a stable baseline $(<10 \%$ change) for at least 30 min was required before application of conditioning stimuli. LTP was elicited using high-frequency stimulation (HFS) consisting of four trains of 50 pulses delivered at $200 \mathrm{~Hz}$ with a $2 \mathrm{~s}$ intertrain interval. The population spike (PS) was depicted as shown in Figure $1 B$. Point $\mathrm{d}$ is the midpoint of a and $c$, and point $\mathrm{m}$ is the intersection of baseline to the ascending curve (s) labeled with a dashed line with dual arrows. The amplitude $(A)$ of PS is calculated using the equation of $A=U_{\mathrm{d}}-U_{\mathrm{b}}\left(U_{\mathrm{d}}\right.$ and $U_{\mathrm{b}}$ represent, respectively, the potential of points $\mathrm{d}$ and $\mathrm{b}$ ). The slope $(S)$ of EPSP is evaluated for the slope of the point $\mathrm{m}$ to point a as follows: $\left(U_{\mathrm{a}}-U_{\mathrm{m}}\right) /\left(T_{\mathrm{a}}-T_{\mathrm{m}}\right) . U_{\mathrm{a}}$ and $U_{\mathrm{m}}$ represent, respectively, the potential of points a and $\mathrm{m}$, and $T_{\mathrm{a}}$ and $T_{\mathrm{m}}$ represent, respectively, the time of points $\mathrm{a}$ and $\mathrm{m}$ (Shirasaka and Wasterlain, 1994; Mazarati et al., 2000; Walling et al., 2004). The calculations were done by a computerized program (RM6240BD; Chengdu, China). For paired-pulse facilitation (PPF) recording, PPF was measured using various interpulse intervals $(50,100$, $150,200,250$, and $300 \mathrm{~ms}$ ) after delivery of the tetanus stimulations. Because PPF is mediated by presynaptic mechanism, changes in PPF after 
various treatments indicate whether a presynaptic mechanism underlies the effect of the treatments (Hou et al., 2006; Veliskova and Velisek, 2007).

Electron microscopy and the image analysis of synapses. The tissue preparation as well as an unbiased stereological sampling and counting were performed as described previously (Geinisman et al., 2004). In brief, the rats were perfused transcardially with $\mathrm{PBS}, \mathrm{pH} 7.4$, and $4 \%$ paraformaldehyde solution after electrophysiological recording. The brain was then removed and fixed in $2.5 \%$ glutaraldehyde for $2 \mathrm{~h}$. After being washed thrice in PBS, the tissue was postfixed in $1 \%$ osmium tetroxide $\left(\mathrm{OsO}_{4}\right)$ for $30 \mathrm{~min}$, dehydrated with graded alcohol and acetone, and then embedded in Epon 812. The ultrathin sections, cut with a diamond knife on a Leica UCT ultramicrotome (Leica, Wetzlar, Germany), were picked up on uncoated 200-mesh copper grids and stained for $25 \mathrm{~min}$ in uranyl acetate and lead citrate. The grids were viewed by a transmission electron microscope (FEI Tecnai $G^{2}$ 12; Eindhoven, The Netherlands). Synapses were identified with the aid of electron micrographs of serial sections by the presence of synaptic vesicles in the presynaptic terminal and the postsynaptic density (PSD) in a postsynaptic element. The width of synaptic cleft (SC) and the thickness of PSD were analyzed according to previously reported protocol (Rabenstein et al., 2005) using NIH Image J software. Statistical analysis of PSD was performed by taking the average density from each synapse using Student's $t$ test.

Preparation of synaptosome and analysis of glutamate release. The synaptosome (P2 fraction) was prepared by a previously established method (Bradford, 1976; McGahon and Lynch, 1996): the hippocampal CA3 region was excavated and homogenized in $320 \mathrm{~mm}$ ice-cold sucrose and centrifuged at $800 \times g$ for $5 \mathrm{~min}$ at $4^{\circ} \mathrm{C}$. The resulting supernatant was further centrifuged at $20,000 \times \mathrm{g}$ for $15 \mathrm{~min}$ at $4^{\circ} \mathrm{C}$, and $\mathrm{P} 2$ fractioncontaining synaptosome was collected. After preincubation of $\mathrm{P} 2$ at $37^{\circ} \mathrm{C}$ for $15 \mathrm{~min}$ in oxygenated Krebs solution containing $2 \mathrm{mM} \mathrm{CaCl}_{2}$, the samples were aliquot onto Millipore (Billerica, MA) filters $(0.45 \mu \mathrm{m})$ and rinsed under vacuum. The filter was incubated in $250 \mu$ l oxygenated Krebs solution at $37^{\circ} \mathrm{C}$ for $3 \mathrm{~min}$ in the presence or absence of $\mathrm{KCl}(50$ $\mathrm{mm}$ ), and the filtrate was collected and stored. For measurement of glutamate (Ordronneau et al., 1991), samples (50 $\mu$ l) or glutamate standards ( $50 \mu \mathrm{l} ; 50 \mathrm{~nm}$ to $10 \mathrm{~mm}$ prepared in $100 \mathrm{~mm} \mathrm{PBS}, \mathrm{pH} 8.0$ ) were added to 96-well plates coated with glutaraldehyde ( $320 \mu \mathrm{l} ; 0.5 \%$ in $100 \mathrm{~mm}$ PBS, $\mathrm{pH} 4.5$ ), incubated for $2 \mathrm{~h}$ at $37^{\circ} \mathrm{C}$, and washed in $100 \mathrm{~mm}$ PBS. To bind any unreacted aldehydes, $100 \mathrm{~mm}$ ethanolamine in $100 \mathrm{~mm}$ PBS $(320 \mu \mathrm{l})$ was added, and incubation continued for $60 \mathrm{~min}$ at $37^{\circ} \mathrm{C}$. Plates were washed with PBS containing $0.5 \%$ Tween 20 (PBS-T), nonspecific binding was blocked by incubation for $60 \mathrm{~min}$ with donkey serum $(200 \mu \mathrm{l} ; 3 \%$ in PBS-T), and $100 \mu$ l of mouse anti-glutamate antibody (G9282, 1:5000 in PBS-T; Sigma) was added. Samples were incubated overnight at $4^{\circ} \mathrm{C}$, washed with PBS-T, and reacted with anti-mouse horseradish peroxidase-conjugated secondary antibody ( $95 \mu \mathrm{l} ; 1: 10,000$ in PBS-T; GE Healthcare, Little Chalfont, UK). After incubation for $60 \mathrm{~min}$ at room temperature, $3,3^{\prime}, 5,5^{\prime}$-tetramethylbenzidine liquid substrate was added, and incubation continued for $60 \mathrm{~min}$ at room temperature. $\mathrm{H}_{2} \mathrm{SO}_{4}(4 \mathrm{M}$; $50 \mu \mathrm{l}$ ) was added to stop the reaction, and optical densities were determined at $450 \mathrm{~nm}$ using a multiwell plate reader. Values were calculated with reference to the standard curve, corrected for protein (Bradford, 1976; McGahon and Lynch, 1996), and expressed as micromoles of glutamate per milligram of protein.

Assay of GSK-3 activity. The hippocampus was homogenized as described above, and the homogenate was centrifuged at 12,000 $\times \mathrm{g}$ for 20 $\min$ at $4^{\circ} \mathrm{C}$. The resulting supernatant was assayed for GSK-3 activity using phospho-GS peptide 2 (Millipore) as described previously (Liu et al., 2004). Briefly, $7.5 \mu \mathrm{g}$ of protein was incubated for $30 \mathrm{~min}$ at $30^{\circ} \mathrm{C}$ with $20 \mu \mathrm{M}$ peptide substrate and $200 \mu \mathrm{M} \gamma-{ }^{32} \mathrm{P} \mathrm{ATP}(1500 \mathrm{cpm} / \mathrm{pmol}$ ATP $)$ in $30 \mathrm{~mm}$ Tris, $\mathrm{pH}$ 7.4, $10 \mathrm{~mm} \mathrm{MgCl}_{2}, 10 \mathrm{~mm} \mathrm{NaF}, 1 \mathrm{~mm} \mathrm{Na} \mathrm{VO}_{4}, 2 \mathrm{~mm}$ EGTA, and $10 \mathrm{~mm} \beta$-mercaptoethanol in a total volume of $25 \mu \mathrm{l}$. The reaction was stopped with $300 \mathrm{~mm}$ o-phosphoric acid $(25 \mu \mathrm{l})$. Then the reaction mixture $(5 \mu \mathrm{l})$ was applied in triplicates to phosphocellulose units. The filters were washed three times with $75 \mathrm{~mm}$ o-phosphoric acid, dried, and analyzed by a liquid scintillation counter (1450 MicroBeta JET; PerkinElmer Life and Analytical Sciences, Shelton, CT). Relative activity of GSK-3 activity was expressed.
Cell culture. Primary embryonic hippocampal neurons of the rats were cultured according to the procedure described previously (Meberg and Miller, 2003; Kaech and Banker, 2006). Briefly, the hippocampi of the embryonic rats (18 d, $\sim 10$ embryos/litter, three litters) were collected and incubated with $5 \mathrm{ml}$ of $0.25 \%$ trypsin in D-Hanks for $15 \mathrm{~min}$ and then centrifuged at $1000 \times g$ for $5 \mathrm{~min}$ after addition of $5 \mathrm{ml}$ of the neuronal plating medium containing DMEM/F12 with 10\% fetal bovine serum and $10 \%$ vituline serum, and the cells in the pellet were triturated and plated onto a $60 \mathrm{~mm}$ plastic culture dish $\left(100 \sim 200\right.$ neurons $\left./ \mathrm{mm}^{2}\right)$ and incubated in a humidified incubator with $5 \% \mathrm{CO}_{2}$ at $37^{\circ} \mathrm{C}$ for $4 \mathrm{~h}$. Then the Neurobasal medium supplemented with 2\% B27 (maintenance medium) was replaced and the cells were cultured for $8 \mathrm{~d}$. The medium was changed every $3 \mathrm{~d}$ with replacement of half volume fresh maintenance medium each time. N2a cells were cultured as described previously (Wang et al., 2006).

Reverse transcription-PCR for measuring the mRNA level of synapsin I. Total RNA was isolated using Trizol according to the manufacturer's instructions (Invitrogen). Then total RNA ( $3 \mu \mathrm{g}$ in $25 \mu \mathrm{l}$ ) was reverse transcribed, and the produced cDNA $(1 \mu \mathrm{l})$ was used to detect the transcripts. The primers used for synapsin I: 5'-GCCCTTCATTGATGCTAAA-3' (forward), 5'-GTGATCCCTTCCGTCCTT-3' (reverse); the primers used for $\beta$-actin: $5^{\prime}$-AGCCTTCCTTCTTGGGTAT- $3^{\prime}$ (forward), 5'-GCTCAGTAACAGTCCGCCTA-3' (reverse). For PCR amplification, 32 cycles was performed, and each cycle was programmed as follows: denaturing at $94^{\circ} \mathrm{C}, 60 \mathrm{~s}$, annealing at $54.2^{\circ} \mathrm{C}, 50 \mathrm{~s}$; and chain extension at $72^{\circ} \mathrm{C}, 1 \mathrm{~min}$. The PCR products were separated on $1.5 \%$ agarose gels and stained with GoldView. The cDNA bands were visualized under UV transillumination and quantitatively analyzed using software BioCaptMW V.10 (Vilber Lourmat, Marne-La-Vallee Cedex 1, France).

Western blotting. For brain samples, the hippocampi taken immediately after electrophysiological recording were homogenized in buffer containing $10 \mathrm{~mm}$ Tris-Cl, pH 7.6, $50 \mathrm{~mm} \mathrm{NaF}, 1 \mathrm{~mm} \mathrm{Na}_{3} \mathrm{VO}_{4}, 1 \mathrm{~mm}$ edetic acid, $1 \mathrm{~mm}$ benzamidine, $1 \mathrm{~mm}$ PMSF, and a mixture of aprotinin, leupeptin, and pepstatin A (10 $\mu \mathrm{g} / \mathrm{ml}$ each). For cell samples, the cells were rinsed twice in ice-cold PBS, $\mathrm{pH} 7.5$, and lysed with buffer containing $50 \mathrm{~mm}$ Tris- $\mathrm{Cl}, \mathrm{pH} 8.0,150 \mathrm{~mm} \mathrm{NaCl}, 1 \% \mathrm{NP}-40,0.5 \%$ sodium deoxycholate, $0.1 \%$ SDS, $0.02 \% \mathrm{NaN}_{3}, 100 \mu \mathrm{g} / \mathrm{ml} \mathrm{PMSF}$, and $10 \mu \mathrm{g} / \mathrm{ml}$ each of the protease inhibitors (leupeptin, aprotinin, and pepstatin A) followed by sonication for $5 \mathrm{~s}$ on ice. Three volumes of the homogenate (for both brain and cell samples) was added to one volume of the extracting buffer containing $200 \mathrm{~mm}$ Tris-Cl, pH 7.6, 8\% SDS, 40\% glycerol. After measurement of protein concentration in the extracts using BCA kit (Pierce, Rockford, IL), a final concentration of $10 \%$ $\beta$-mercaptoethanol and $0.05 \%$ bromophenol blue were added, and the samples were boiled in a water bath for $10 \mathrm{~min}$. The proteins in the extracts were separated by $10 \%$ SDS-PAGE and transferred to nitrocellulose membrane. Immunoreactive materials were detected using a chemiluminescent substrate kit (Pierce) and exposed to CL-XPosure film. The blots were scanned, and the sum optical density was quantitatively analyzed by Kodak Digital Science 1D software (Eastman Kodak, New Haven, CT).

Immunohistochemistry. The rats were killed by overdose of chloral hydrate $(1 \mathrm{~g} / \mathrm{kg})$ and fixed in situ for $20 \mathrm{~min}$ by perfusion of $4 \%$ paraformaldehyde in $24 \mathrm{~mm} \mathrm{NaH}_{2} \mathrm{PO}_{4}-126 \mathrm{~mm} \mathrm{Na}_{2} \mathrm{HPO}_{4}$, $\mathrm{pH} 7.2$, at $4^{\circ} \mathrm{C}$. Coronal brain sections of hippocampal tissue were cut at $35 \mu \mathrm{m}$ using a vibrate microtome (VT1000s; Leica) (Pei et al., 1997). For immunohistochemistry, the sections were incubated for $48 \mathrm{~h}$ at $4^{\circ} \mathrm{C}$ with primary antibodies, and the slices were developed with Histostain-SP kits (Zymed, South San Francisco, CA) and visualized with DAB (Sigma). For immunofluorescence, sections were incubated overnight at $4^{\circ} \mathrm{C}$ with primary antibodies as indicated in the related figures, and the immunoreactivity was measured using rhodamine red-X- or Oregon Green 488-conjugated secondary antibodies (1:1000; Invitrogen). For the triple-labeling studies, Hoechst 33258 ( $1 \mu \mathrm{g} / \mathrm{ml}$; Sigma) was used for the nuclear staining. For each primary antibody, three to five consecutive sections from each brain were used. The images were observed by using a laser confocal microscope (FV500; Olympus, Tokyo, Japan) or a fluorescence microscopy (System Microscopy IX70; Olympus). For cell studies, cells were cultured 
on coverslips and fixed with $4 \%$ paraformaldehyde for $1.5 \mathrm{~h}$ at $4^{\circ} \mathrm{C}$ and then incubated for $12 \sim 36 \mathrm{~h}$ at $4^{\circ} \mathrm{C}$ with primary antibodies overnight. The rest of the processes were the same as the brain samples as described above.

Statistical analysis. Data were analyzed by using SPSS 11.0 statistical software (SPSS, Chicago, IL), and the one-way ANOVA procedure followed by Student's $t$ tests was used to determine the differences between the groups.

\section{Results}

Upregulation of GSK-3 inhibits LTP

To induce and record LTP, we placed a stimulating electrode in the perforant path and a recording electrode in CA 3 region of rat hippocampus through a stereotaxic instrument. A drug administrating system was placed in CA3 region near the recording electrode as indicated (Fig. $1 A$ ). We used wortmannin (a general activator), $\mathrm{LiCl}$ (the seminal inhibitor), or SB216763 (a specific inhibitor) to manipulate the activity of GSK-3. The drugs were administered 30 min before recording, and an HFS was supplied to evoke LTP. The changes in amplitude of PS and slope of EPSP after HFS were calculated to evaluate the alterations of LTP (Fig. $1 B$ ). We observed that the amplitude of PS and slope of EPSP were much lower in rats treated with wortmannin than those treated with vehicles; however, this inhibition was prominently antagonized by a simultaneous addition of $\mathrm{LiCl}$ or SB216763 (Fig. 1C-E). Without

HFS, we did not observe any obvious change in the amplitude of PS and slope of EPSP when GSK-3 manipulators were added 30 min before the recording (Fig. $1 D, E$, from -30 to $0 \mathrm{~min}$ ); furthermore, by prolonged recording for up to $2 \mathrm{~h}$ to detect the effects of wortmannin, $\mathrm{LiCl}$ or SB216763 alone on baseline responses without HFS, we also did not detect any significant alterations compared with the vehicle control (Fig. $1 F$ ). These data suggest that GSK-3 may not affect the basal synaptic transmission. To rule out any possible artifacts that may be caused by the ionic effect of lithium or chloride on the preserved LTP, we used $\mathrm{NaCl}$ with the same concentration as $\mathrm{LiCl}$ in the study, but no protection by $\mathrm{NaCl}$ was detected (data not shown). Additionally, a full range of the input-output recording for normalizing the condition was also performed before the study (data not shown).

To confirm the role of GSK-3, we transiently expressed wtGSK- $3 \beta$, dnGSK- $3 \beta$, or pcDNA into the rat brains. The efficient expression of GSK-3 $\beta$ (see Fig. $4 A$, HA-tag) in the region of CA3 (Fig. $1 A$, black square) was confirmed by examination using a fluorescence microscope immediately after the electrophysiological recording ( $\sim 26 \mathrm{~h}$ after the transfection). After HFS, the PS amplitude increased to approximately 2.2- to 2.6-fold of the basal level in rats expressing pcDNA, whereas the increase was only approximately 1.4- to 1.6-fold of the basal level in rats overexpressing wtGSK-3 $\beta$. The levels of PS amplitude were restored to approximately 2.0 - to 2.3 -fold of the normal basal levels in rats expressing dnGSK-3 $\beta$ and in rats expressing wtGSK-3 $\beta$ with simultaneous treatment of SB216763 (Fig. 1G). Similar results were also observed by EPSP analysis (Fig. $1 H$ ). Together, these data strongly suggest that upregulation of GSK-3 $\beta$ inhibits LTP.
B
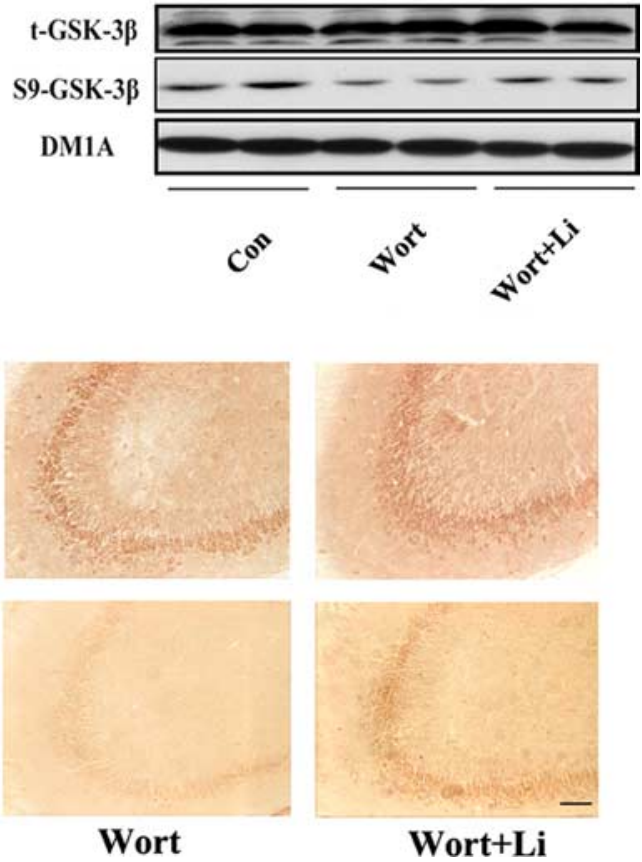

Wort

Wort+Li

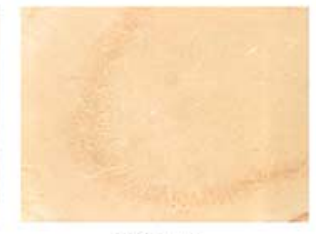

lation. The drug administration and the electrophysiological recording were performed as described in Figure 1. A, After the recording, the extract of hippocampal CA3 was prepared, and the activity of GSK-3 was measured by a ${ }^{32}$ P-labeling assay using phospho-GS peptide 2 as a specific substrate. ${ }^{* *} p<0.01$ recording as described in Figure 1. Scale bar, $100 \mu \mathrm{m}$.

To verify the status of GSK-3 during the pharmacological treatments as shown in Figure $1 C-E$, we measured the activity of GSK-3 by a ${ }^{32} \mathrm{P}$-labeling assay using a specific substrate phospho-GS peptide 2 . We found that wortmannin treatment increased the activity of GSK-3 to 2.9-fold of the control level, and the activation of GSK-3 was partially antagonized by pretreatment with $\mathrm{LiCl}$ and SB216763 (Fig. 2A). Additional studies by Western blotting and immunocytochemistry demonstrated that wortmannin markedly reduced the inhibitory phosphorylation of GSK-3 $\beta$ at Ser9, and this reduction was prevented by $\mathrm{LiCl}$ treatment in the CA3 region of the hippocampus (Fig. $2 B, C$ ) ( $n=5, p<0.01$ for Western blotting analysis). No obvious change was seen in the total level of GSK-3 $\beta$ (Fig. $2 B, C$ ). These results not only further assure the efficiency of the chemicals on GSK-3 activity, but also confirm the role of GSK-3 in modulating LTP. Although SB216763 inhibited the activity of GSK-3 (Fig. $2 A$ ), it did not affect significantly the Ser9 phosphorylation of GSK-3 $\beta$ (data not shown), suggesting that SB216763 inhibits GSK-3 with different mechanism from lithium.

Upregulation of GSK-3 reduces presynaptic transmission and glutamate release

To explore whether the presynaptic transmitter release is involved in the suppressed LTP induced by GSK-3 upregulation, we applied PPF recording immediately after HFS or $1 \mathrm{~h}$ after the HFS. We found that the relative ratio of the second pulse-induced PS amplitude over the first pulse-induced PS amplitude (i.e., PS2/PS1) decreased significantly in wortmannin-treated rats compared with the vehicle-treated ones, and simultaneous application of SB216763 prominently reserved the inhibition (Fig. 
A

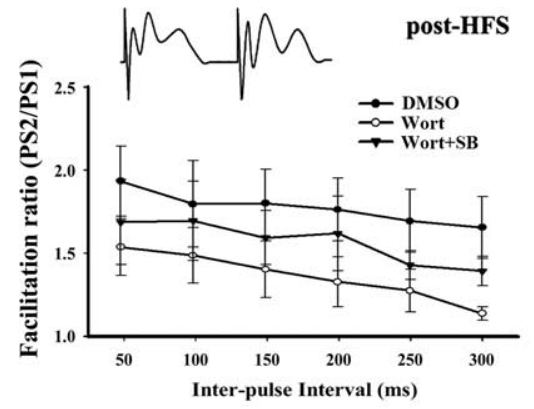

C

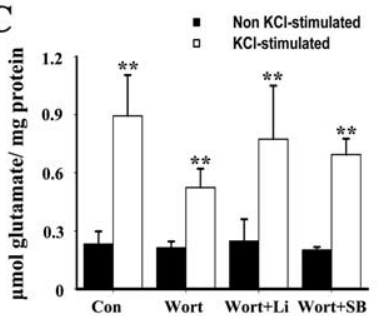

\section{D}

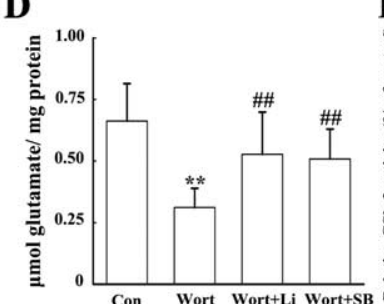

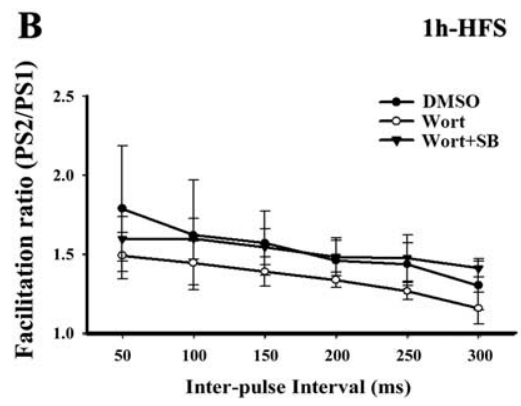

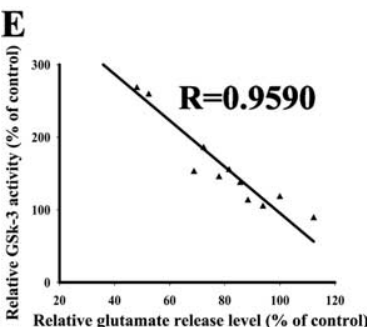

Figure 3. Activation of GSK-3 reduces presynaptic transmission. $A, B$, The relative ratio of the second pulse-induced PS (PS2) to the first pulse-induced PS (PS1) recorded immediately after HFS ( $\boldsymbol{A})$ or $1 \mathrm{~h}$ after the HFS $(\boldsymbol{B})$ with the treatments as indicated $(n=$ 5 for each data point). $C$, The released levels of glutamate in $\mathrm{K}^{+}$-stimulated and unstimulated synaptosome fractions prepared from hippocampal CA3 region of the HFS-potentiated rats. ${ }^{* *} p<0.01$, versus each unstimulated control (Con). $\boldsymbol{D}$, The $\mathrm{K}^{+}$. evoked release of glutamate normalized to each of the unstimulated samples. ${ }^{* *} p<0.01$, versus vehicle control; ${ }^{\# \#} p<0.01$, versus Wort $(n=5$; means \pm SD). $\boldsymbol{E}$, The bivariate correlation analyses of relative GSK-3 activity and relative glutamate release level.

$3 A)$. A similar profile was also observed when the PPF was recorded after $1 \mathrm{~h}$ of the HFS (Fig. $3 B$ ). These results suggest that the presynaptic factors may play an important role in the GSK-3induced LTP inhibition. To further verify the presynaptic involvement in the altered LTP induced by manipulation of GSK-3, we isolated the synaptosome and measured the $\mathrm{K}^{+}$-evoked synaptosomal release of glutamate in the tetanized $\mathrm{CA} 3$ region of the hippocampus. Compared with each unevoked control, $\mathrm{K}^{+}$stimulation increased significantly the release of glutamate (Fig. 3C). When the $\mathrm{K}^{+}$-stimulated release of glutamate was normalized to each unevoked control, we observed that the level of glutamate in wortmannin-treated rats decreased to $\sim 59 \%$ of the control level, and pretreatment with $\mathrm{LiCl}$ or SB216763 restored the glutamate content to $\sim 87 \%$ and $\sim 78 \%$ of the control level, respectively (Fig. 3D). Statistical analysis revealed a highly negative correlation between the relative activity of GSK-3 and the relative level of glutamate release $(p<0.001 ; r=0.9590)$ (Fig. $3 E)$. These results suggest that inhibition of LTP by GSK-3 upregulation involves an impaired presynaptic release of glutamate.

\section{Upregulation of GSK-3 reduces expression and clustering of synapsin I}

The presynaptic release of glutamate is tightly regulated by synapsin I (SynI), a synaptic vesicle protein (Nichols et al., 1992). To explore whether GSK-3 affects SynI, we transiently expressed wtGSK-3 $\beta$, dnGSK-3 $\beta$, or pcDNA in the hippocampal CA3 region of the rats. LTP was recorded as indicated in Figure $1 A$ at $24 \mathrm{~h}$ after the transfections, the level of SynI was measured by immunofluorescence staining. SynI was detected in both the cytoplasm and the processes of neurons in the pcDNA-transfected region of the brain slices. The staining of SynI was almost completely diminished in neurons expressing wtGSK-3 $\beta$ and was significantly restored when dnGSK-3 $\beta$ was expressed (Fig. 4A). These results indicate that activation of GSK-3 inhibits the ex- pression of SynI after induction of LTP. To explore whether GSK-3 affects SynI independent of LTP, we measured the expression of SynI in $8 \mathrm{~d}$ in vitro (DIV) primary hippocampal neurons without potentiation treatment. Compared with nontransfected neurons in the same visual view, SynI staining became much weaker in neurons overexpressing wtGSK-3 $\beta$-HA (Fig. $4 B$, arrowheads). We selected 8-12 neurons from four independent experiments and analyzed the staining of Syn I in GSK-3 $\beta$-positive and -negative cells. We found that the staining intensity of Syn I in GSK- $3 \beta$-positive cells decreased to $~ 35 \%$ of the control cells, in which GSK-3 $\beta$ (HA-tag) was negative $(p<0.01)$. Additional study in $\mathrm{N} 2$ a cells revealed that upregulation of GSK-3 decreased SynI protein (Fig. 4C) and mRNA (Fig. 4D) to $\sim 75 \%$ and $\sim 65 \%$ of the control levels $(p<0.01)$, respectively. These data demonstrate that GSK-3 can inhibit the expression of SynI independent of LTP, which may contribute to the decreased presynaptic release of glutamate (Nichols et al., 1992) and the suppressed induction of LTP.

Unlike the genetic manipulation as described above, the effects of pharmacological GSK-3 modulators on LTP are immediate. To further explore how SynI participates in these immediate effects, we measured SynI clustering. We found in 8 DIV primary hippocampal neurons that the clustering of SynI decreased significantly assayed by immunofluorescence staining after wortmannin treatment and was restored to the normal level when $\mathrm{LiCl}$ or SB216763 was simultaneously administered (Fig. 5), indicating that GSK-3 activation interrupt SynI clustering. These data may at least partially explain the immediate effect of GSK-3 modulators on the altered glutamate release and LTP.

To exclude the possibility that the decrease in SynI clusters was induced by general synapse loss, we performed doubleimmunostaining study by using another synaptic marker, synaptophysin I (Eastwood et al., 1995). No significant change in the level of synaptophysin I was detected after wortmannin treatment (supplemental Fig. 1, available at www.jneurosci.org as supplemental material), confirming the effect of GSK-3 on the formation of SynI clusters.

\section{Upregulation of GSK-3 reduces the level of PSD93 and NR2A/B}

To explore whether GSK-3 also affects the postsynaptic associated proteins, we measured the levels of PSD93, NMDA receptor 1 (NR1) and NR2A/B, synaptophysin, and PKAII $\alpha$. Among these proteins, only the level of PSD93 was significantly decreased after wortmannin treatment in the hippocampal lysates, which was partially restored when GSK-3 was simultaneously inhibited by SB216763 (Fig. 6A). To further confirm the changes of these postsynaptic proteins, we prepared the $\mathrm{P} 2$ fraction to enrich the synaptic associated proteins (Hooper et al., 2007). We found that the levels of NR2A/B subunits were also reduced in addition to a more prominent decrease of PSD93 after wortmannin treatment, and these proteins were partially restored when GSK-3 was si- 
multaneously inhibited by SB216763 in this $\mathrm{P} 2$ fraction (Fig. $6 \mathrm{~B}$ ). Statistical analysis revealed a highly negative correlation between the relative activity of GSK-3 and the relative levels of PSD93 $(r=0.9599)$ or NR2A/B $(r=0.9406)$ (Fig. $6 C, D)$. These data suggest that GSK-3 also influences the postsynaptic transmission.

\section{Upregulation of GSK-3 impairs the ultrastructure of the synapses}

To explore the morphological changes associated with the suppressed LTP by GSK-3 activation, we measured the morphology of synapses in the tetanized CA3 region of the hippocampus using an electron microscope. Compared with vehicle controls, prominent synaptic impairments, including the reduced size of presynaptic active zone, thinner PSD, and broader SCs, were observed after wortmannin treatment. These changes were restored almost to the control level when SB216763 was simultaneously administered (Fig. 7A). To quantitatively evaluate the alterations, we selected those synapses with synaptic vesicles in the presynaptic terminal and PSD in a postsynaptic compartment for the analysis. We found that alterations of the apparent thickness of PSD and the width of SC in the synapses were statistically significant $(p<0.01)$ when GSK-3 activity was manipulated (Fig. $7 B$ ). These data further support that both presynaptic and postsynaptic loci are implicated in the altered plasticity of synapses in response to GSK-3-mediated inhibition of LTP.

\section{Discussion}

We have previously reported that activation of GSK-3 causes spatial memory deficits in rats (Liu et al., 2003). Transgenic mice that conditionally overexpress GSK-3 $\beta$ in brain also show spatial learning impairment (Hernandez et al., 2002; Engel et al., 2006). However, the underlying mechanism for GSK-3-involved learning/ memory deficits is not clear. It is well recognized that synaptic plasticity, which can be assessed by altered LTP and/or morphology of synapses, is a prerequisite of learning and memory. By measuring the alterations of the amplitude of PS and the slope of EPSP, the accepted parameters for the in vivo measurement of LTP (Richter-Levin and Segal, 1991), and manipulating the activity of GSK-3 both pharmacologically and genetically, we demonstrated in the present study that overactivation of GSK-3 inhibited the induction of LTP in rat hippocampus. With activation of GSK-3, both presynaptic release of glutamate and postsynaptic expression of PSD93 and NR2A/B proteins decreased prominently, and the LTP-associated synapse impairments were also observed morphologically. The above lesions were partially but significantly restored with a concomitant inhibi-
$\mathbf{A}$

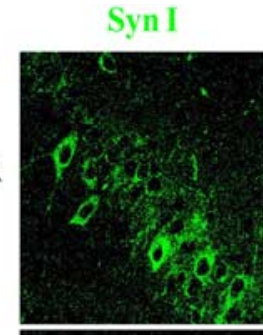

HA-tag

Hoechst
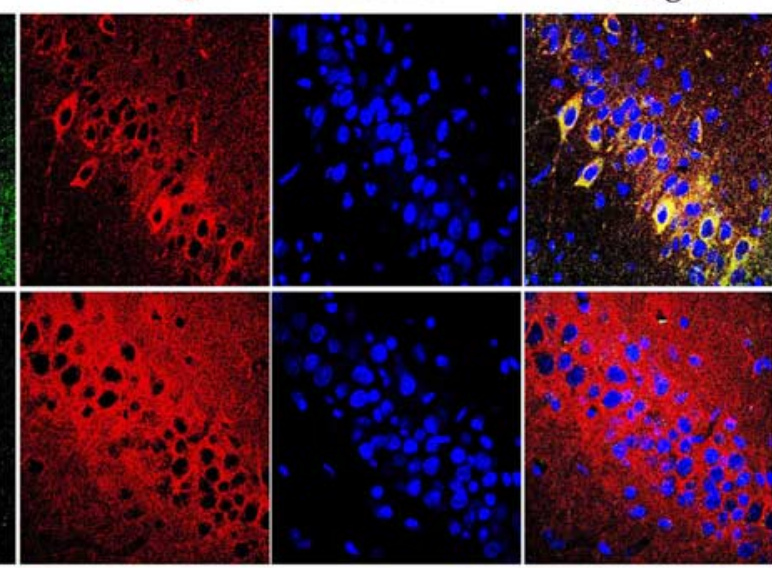

$\mathbf{B}$

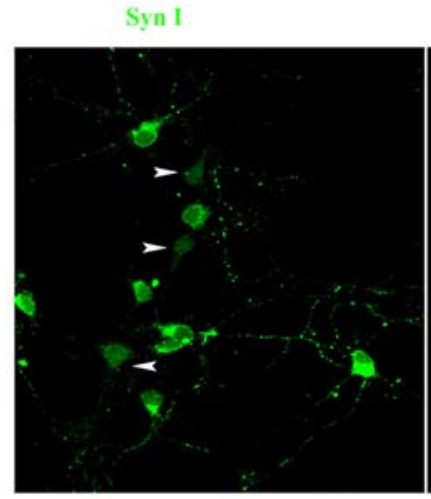

HA-tag
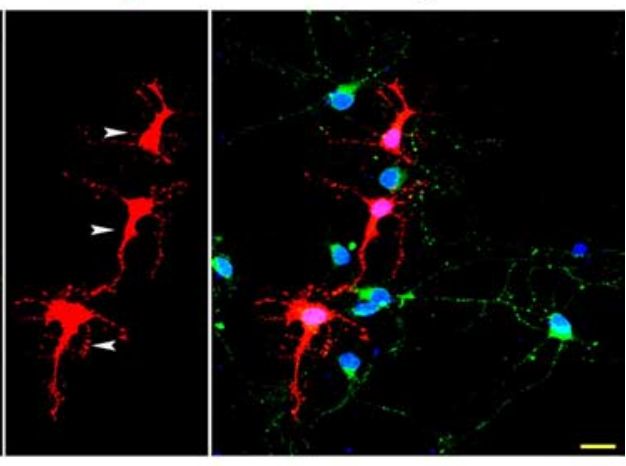

D

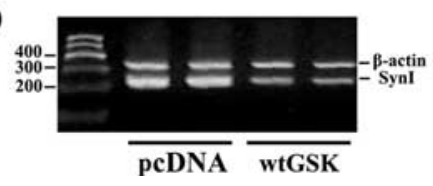

Figure 4. Activation of GSK-3 reduces expression of Synl. $A$, The effect of GSK-3 on Synl measured in the tetanized rat brains: the wtGSK-3 $\beta$, dnGSK-3 $\beta$, and pcDNA were transfected respectively into CA3 region of the rat brains for $24 \mathrm{~h}$. Then, the rats received the electrophysiological recording as described in Figure 1 , and the brain slices in the area marked as a square in Figure $1 \mathrm{~A}$ were prepared. Synl (green) was colabeled with HA-GSK-3 $\beta$ (red), and Hoechst was used to stain the cell nuclei. Scale bar, $10 \mu \mathrm{m}$. $\boldsymbol{B}$, The effect of GSK-3 on Synl measured in primary culture: the HA-tagged wtGSK-3 $\beta$ plasmid was transfected into 8 DIV hippocampal neurons for $24 \mathrm{~h}$, and then Synl (green) was colabeled with HA-GSK-3 $\beta$ (red, HA-tag). The arrowheads show a negative correlation of Synl and HA-GSK-3 $\beta$ staining. Scale bar, $20 \mu \mathrm{m}$. C, D, The effect of GSK-3 on Synl measured in N2a cells: the wtGSK-3 $\beta$, dnGSK-3 $\beta$, and pcDNA were transfected respectively into wild-type N2a cells, and Synl protein ( $($ ) and mRNA (D) levels were measured by Western blotting $(n=4)$ and reverse transcription-PCR $(n=4)$ at $48 \mathrm{~h}$ after the transfection.

tion of the GSK-3 upregulation. We also observed that inhibition of basal GSK-3 activity seemed not to affect the synaptic transmission. These results reveal that GSK-3 activation impairs synaptic plasticity both functionally and structurally, which may underlie the GSK-3involved deficits in learning and memory. Without HFS, we did not observe any obvious change in the amplitude of PS and the slope of EPSP when GSK-3 manipulators were added 30 min before the recording, suggesting that GSK-3 may not affect the basal synaptic transmission.

In this study, LTP was recorded in vivo through the perforant 

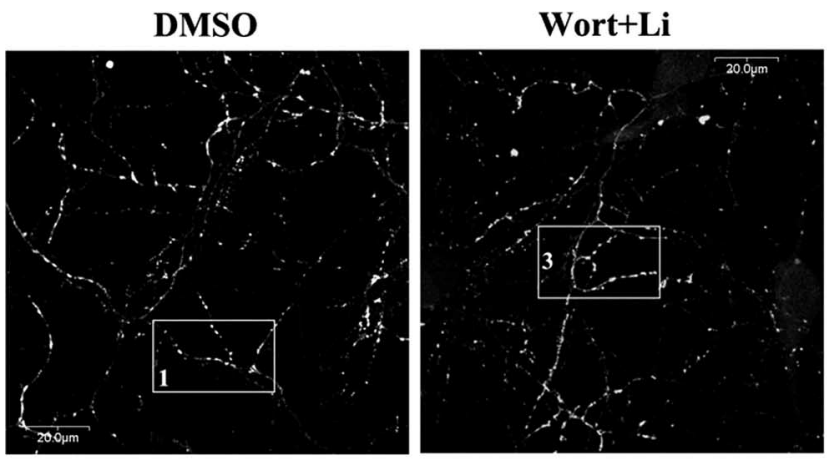

Wort

Wort + SB
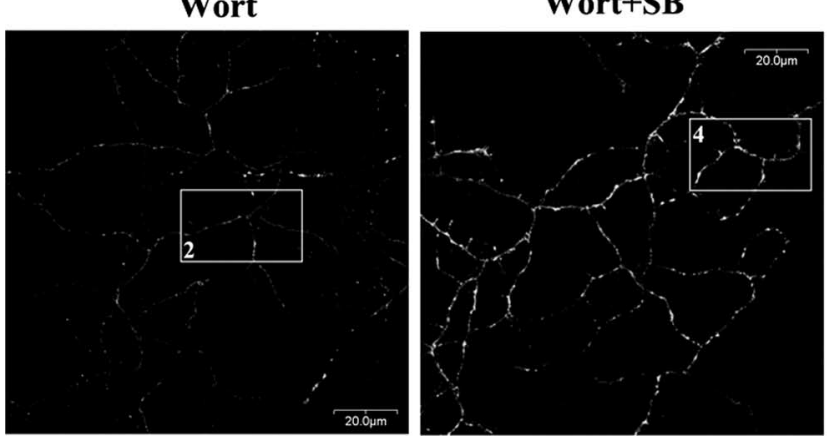

Figure 5. Activation of GSK-3 reduces Synl clusters (arrowheads) in primary hippocampal neurons. The rat embryonic (18 d) hippocampal neurons were cultured for 8 DIV. Synl cluster was measured by immunofluorescence staining after the treatment with the chemicals as indicated for $2 \mathrm{~h}$. The right panels are shown with higher magnifications. The images are representatives of five independent experiments. Scale bar, $20 \mu \mathrm{m}$.

A
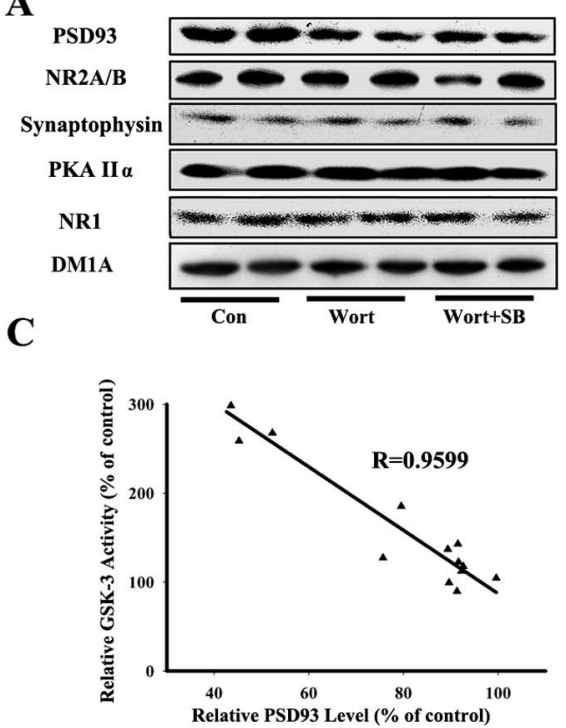

B

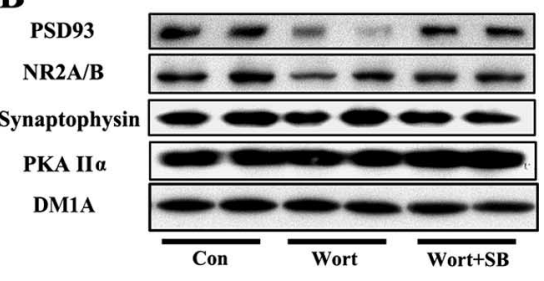

D

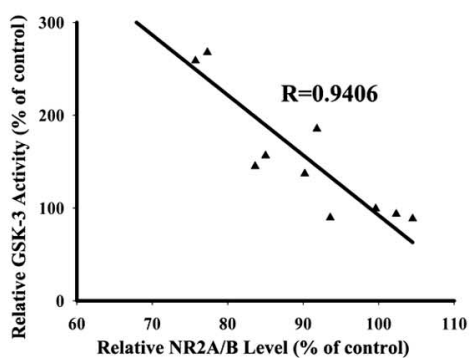

Figure 6. Activation of GSK-3 decreases the levels of synapse-associated proteins. The drug administration and the electrophysiological recording were performed as described in Figure 1. $\boldsymbol{A}, \boldsymbol{B}$, After the recording, the brain extracts $(\boldsymbol{A})$ or $\mathrm{P} 2$ fraction $(\boldsymbol{B})$ were prepared from $C A 3$ region of the hippocampus, and Western blotting $(\boldsymbol{A}, \boldsymbol{B})$ was performed. The blots were representatives of three independent experiments. C, D, The bivariate correlation analyses of relative GSK-3 activity and relative PSD93 or NR2A/B level.

path-CA3 pathway of the hippocampus, an information processor responsible for spatial learning and memory. Studies have demonstrated that direct projection from the perforant path to CA3 mediates distinct and essential functions (Marr, 1971; Morris and Mcnaughton, 1987), and plasticity induced in the direct
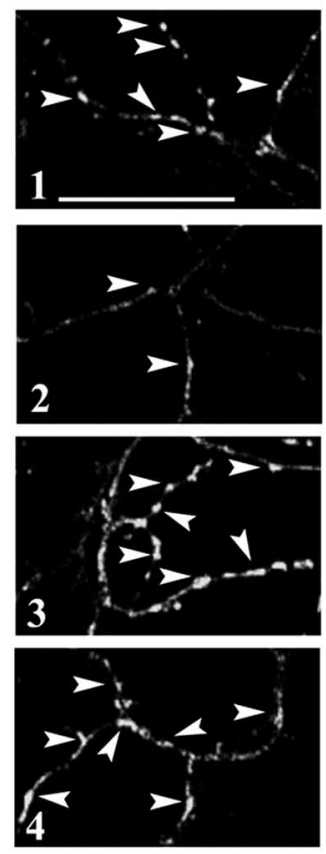

perforant path-CA3 projection during learning serves subsequently as the primary input for memory (Treves and Rolls, 1994). Associative LTP can be induced in the perforant path-CA3 pathway, and this form of LTP plays an important role in the hippocampal information processing (Berger and Yeckel, 1991; Do et al., 2002). This summing-up evidence directed us to the design of the LTP study as shown in Figure $1 \mathrm{~A}$. Using this setting, we successfully recorded the reduction of the amplitude of PS and the slope of EPSP by activating GSK-3. The results suggested that GSK-3 may affect learning and memory through participating in the regulation of perforant path-CA3 pathway.

Synaptic transmission in the nerve system involves coherent presynaptic and postsynaptic actions. In this study, we reported an apparently inhibited presynaptic activation after upregulation of GSK-3. Among various presynaptic elements involved in the formation of LTP, glutamate release has brought great attention (Luscher et al., 1998; Bortolotto et al., 1999). Previous studies in the tetanized rat tissues have revealed an LTP-associated increase in glutamate release (Lynch et al., 1990; Bliss and Collingridge, 1993; Canevari et al., 1994), which was inhibited by wortmannin treatment (Kelly and Lynch, 2000). Here, we also observed a significant inhibition of LTP-associated glutamate release after wortmannin treatment. Furthermore, this inhibition was greatly rescued by lithium or SB216763, which points to a role of GSK-3 in the LTPassociated reduction of glutamate release. An effective presynaptic vesicle release is essential for a functional synapse. Therefore, we speculate that the impaired glutamate release may be at least partially responsible for the decreased presynaptic activation and inhibition of LTP by GSK-3 activation.

The presynaptic release of neurotransmitters involves synaptic vesicleassociated proteins including SynI (Greengard et al., 1993; Pieribone et al., 1995). A locally high level of SynI has been considered to be a marker of synaptic plasticity in neural networks (Melloni et al., 1993). An increased SynI immunoreactivity was detected during LTP in rat hippocampus (Sato et al., 2000), whereas deletion of SynI retarded the formation of synapse in neuronal cultures (Chin et al., 1995; Ferreira et al., 1998). Mice lacking SynI show apparent impairment of presynaptic function and depletion of synaptic vesicles in nerve terminals (Rosahl et al., 1995; Terada et al., 1999). Here, we also found that upregulation of GSK-3 significantly inhibited the expression of SynI at both the mRNA and 
protein levels. Because the in vivo staining of SynI was performed in the tetanized brain tissue, the altered SynI expression can be either cause or consequence of the altered LTP. To verify this, we performed the in vitro studies using primary neuron culture and N2a cell line. We found that activation of GSK-3 could suppress the expression of SynI independent of highfrequency stimulation. These results not only provide a direct link between GSK-3 and SynI, but also suggest that the alteration of SynI may be upstream of the altered LTP. In our study, we found consistently that inhibition of basal GSK-3 by dnGSK-3 did not affect the expression of SynI, although activation of GSK-3 prominently decreased the level of SynI. These results suggest the gain of toxic function of GSK-3 activation. The effect of wortmannin on LTP is immediate. To understand whether the effect of wortmannin on SynI is also immediate, we measured the SynI clustering in 8 DIV hippocampal neurons, which is an immediate response of neurons to high levels of neuronal activity and is a critical step for neurotransmitter release (Hilfiker et al., 1999; Chi et al., 2001; Bloom et al., 2003). We found that manipulation of GSK-3 activity significantly affected the axonal clustering of SynI. To confirm that the decreased SynI clustering was not caused by a general loss of synapses, we did double-staining studies with SynI and synaptophysin I. The results confirmed that the synapses were not obviously affected, although the number of the clusters was remarkably decreased after GSK-3 activation. Based on these data, we speculate that the decreased SynI clustering and/or expression may play a crucial role in the GSK-3-induced suppression of presynaptic release of glutamate and thus contribute to the inhibited LTP. How exactly GSK-3 affects SynI needs additional investigation.

Examined by a transmission electron microscope, a significant damage in PSD was also evident when GSK-3 was activated. Therefore, we measured the levels of several synaptic associated proteins (Gardoni et al., 1998; Teter and Ashford, 2002), including PSD93, NR2A/B, NR1, synaptophysin, and PKAII $\alpha$, in the crude extracts and the $\mathrm{P} 2$ fraction of the tetanized CA3 region of the hippocampus. We found that only PSD93 and NR2A/B were decreased after activation of GSK-3, and they were partially recovered when GSK-3 was simultaneously inhibited. These data suggest that activation of GSK-3 restricts the LTP-associated expression of PSD proteins. Although it was proposed that inhibition of GSK-3 by lithium might increase the levels of synaptic proteins (Salinas and Hall, 1999), we are not able to conclude at this stage whether GSK-3 acts directly on the PSD proteins.

Together, we found here that activation of GSK-3 inhibits LTP and causes significant presynaptic and postsynaptic damages in synapses. According to our findings and the well established knowledge on the subject, we propose that GSK-3 activation may inhibit the expression and/or clustering of SynI, which in turn suppresses glutamate release and presynaptic activation and thus inhibits LTP. The suppression of LTP leads to decreased synthesis of synaptic proteins that may inversely aggravate the inhibition of LTP. These impairments together will damage the synaptic plasticity of the neurons and thus contribute to the learning/memory

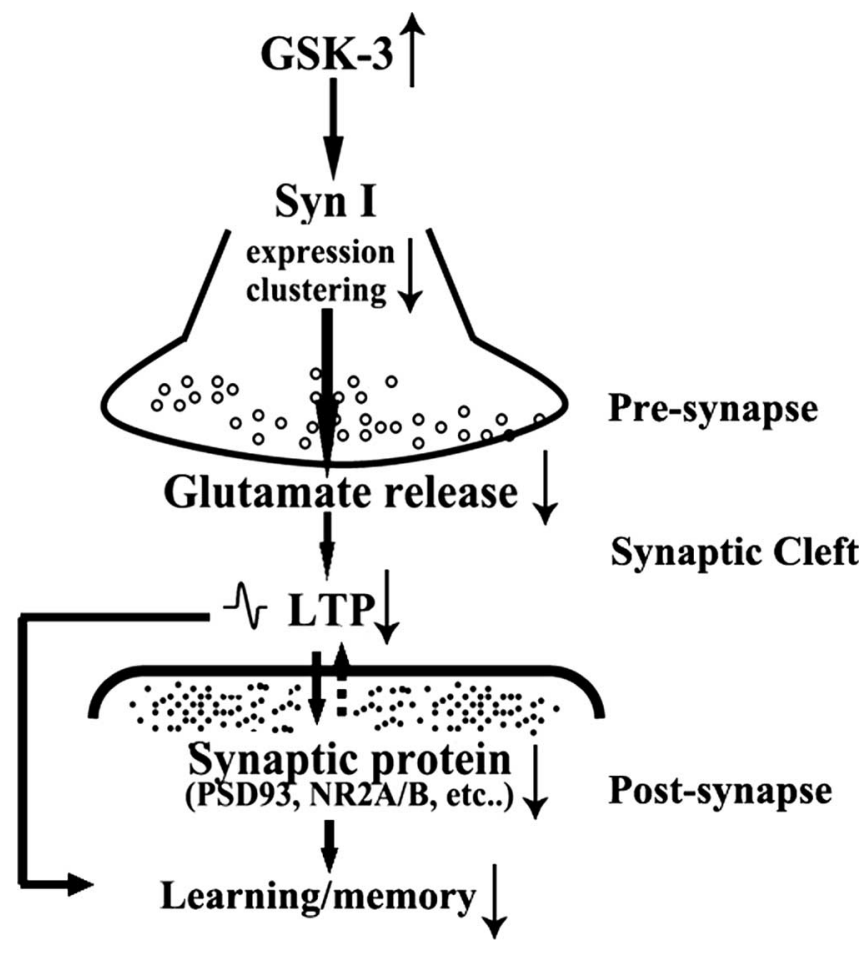

Figure 8. A proposed scheme for GSK-3-involved suppression of synaptic transmission. According the results observed in our study, we propose that activation of GSK-3 inhibits the expression and/or clustering of Synl, which in turn suppresses glutamate release and inhibits induction of LTP. The suppression of LTP then results in decreased synthesis of PSD proteins, and the decreased postsynaptic response inversely restricts the LTP. These impairments together may eventually lead to learning/memory deficits.

deficits (Fig. 8). Our findings not only unveil the functional and structural bases for the GSK-3-involved memory deficits, but also imply that proper regulation of GSK-3 activity may favor the preservation of memory in some neurological disorders, such as AD. 


\section{References}

Berger TW, Yeckel M (1991) Long-term potentiation of entorhinal afferents to the hippocampus: enhanced propagation of activity through the trisynaptic pathway. In: Long-term potentiation: a debate of the current issues (Baudry M, Davis JL, eds), pp 327-356. Cambridge, MA: MIT.

Bliss TV, Collingridge GL (1993) A synaptic model of memory: Long-term potentiation in the hippocampus. Nature 361:31-39.

Bliss TV, Lomo T (1973) Long-lasting potentiation of synaptic transmission in the dentate area of the anaesthetized rabbit following stimulation of the perforant path. J Physiol (Lond) 232:331-356.

Bloom O, Evergren E, Tomilin N, Kjaerulff O, Low P, Brodin L, Pieribone VA, Greengard P, Shupliakov O (2003) Colocalization of synapsin and actin during synaptic vesicle recycling. J Cell Biol 161:737-747.

Bortolotto ZA, Fitzjohn SM, Collingridge GL (1999) Roles of metabotropic glutamate receptors in LTP and LTD in the hippocampus. Curr Opin Neurobiol 9:299-304.

Bradford HF, Richards CD (1976) Specific release of endogenous glutamate from piriform cortex stimulated in vitro. Brain Res 105:168-172.

Canevari L, Richter-Levin G, Bliss TV (1994) LTP in the dentate gyrus is associated with a persistent NMDA receptor-dependent enhancement of synaptosomal glutamate release. Brain Res 667:115-117.

Chapman PF, White GL, Jones MW, Cooper-Blacketer D, Marshall VJ, Irizarry M, Younkin L, Good MA, Bliss TV, Hyman BT, Younkin SG, Hsiao KK (1999) Impaired synaptic plasticity and learning in aged amyloid precursor protein transgenic mice. Nat Neurosci 2:271-276.

Chi P, Greengard P, Ryan TA (2001) Synapsin dispersion and reclustering during synaptic activity. Nat Neurosci 4:1187-1193.

Chin LS, Li L, Ferreira A, Kosik KS, Greengard P (1995) Impairment of axonal development and of synaptogenesis in hippocampal neurons of synapsin I-deficient mice. Proc Natl Acad Sci USA 92:9230-9234.

De Sarno P, Bijur GN, Zmijewska AA, Li X, Jope RS (2006) In vivo regulation of GSK3 phosphorylation by cholinergic and NMDA receptors. Neurobiol Aging 27:413-422.

Do VH, Martinez CO, Martinez Jr JL, Derrick BE (2002) Long-term potentiation in direct perforant path projections to the hippocampal CA3 region in vivo. J Neurophysiol 87:669-678.

Eastwood SL, Burnet PW, Harrison PJ (1995) Altered synaptophysin expression as a marker of synaptic pathology in schizophrenia. Neuroscience 66:309-319.

Engel T, Hernandez F, Avila J, Lucas JJ (2006) Full reversal of Alzheimer's disease-like phenotype in a mouse model with conditional overexpression of glycogen synthase kinase-3. J Neurosci 26:5083-5090.

Ferreira A, Chin LS, Li L, Lanier LM, Kosik KS, Greengard P (1998) Distinct roles of synapsin I and synapsin II during neuronal development. Mol Med 4:22-28.

Gardoni F, Caputi A, Cimino M, Pastorino L, Cattabeni F, Di Luca M (1998) Calcium/calmodulin-dependent protein kinase II is associated with $\mathrm{NR} 2 \mathrm{~A} / \mathrm{B}$ subunits of NMDA receptor in postsynaptic densities. J Neurochem 71:1733-1741.

Geinisman Y, Ganeshina O, Yoshida R, Berry RW, Disterhoft JF, Gallagher M (2004) Aging, spatial learning, and total synapse number in the rat CA1 stratum radiatum. Neurobiol Aging 25:407-416.

Greengard P, Valtorta F, Czernik AJ, Benfenati F (1993) Synaptic vesicle phosphoproteins and regulation of synaptic function. Science 259:780-785.

Grimes CA, Jope RS (2001) The multifaceted roles of glycogen synthase kinase $3 \beta$ in cellular signaling. Prog Neurobiol 65:391-426.

Grundke-Iqbal I, Iqbal K, Quinlan M, Tung YC, Zaidi MS, Wisniewski HM (1986a) Microtubule-associated protein tau. A component of Alzheimer paired helical filaments. J Biol Chem 261:6084-6089.

Grundke-Iqbal I, Iqbal K, Tung YC, Quinlan M, Wisniewski HM, Binder LI (1986b) Abnormal phosphorylation of the microtubule-associated protein tau (tau) in Alzheimer cytoskeletal pathology. Proc Natl Acad Sci USA 83:4913-4917.

Hernandez F, Borrell J, Guaza C, Avila J, Lucas JJ (2002) Spatial learning deficit in transgenic mice that conditionally over-express GSK-3beta in the brain but do not form tau filaments. J Neurochem 83:1529-1533.

Hilfiker S, Pieribone VA, Czernik AJ, Kao HT, Augustine GJ, Greengard P (1999) Synapsins as regulators of neurotransmitter release. Philos Trans R Soc Lond B Biol Sci 354:269-279.

Hooper C, Markevich V, Plattner F, Killick R, Schofield E, Engel T, Hernandez F, Anderton B, Rosenblum K, Bliss T, Cooke SF, Avila J, Lucas JJ,
Giese KP, Stephenson J, Lovestone S (2007) Glycogen synthase kinase-3 inhibition is integral to long-term potentiation. Eur J Neurosci 25:81-86.

Hou QL, Gao X, Lu Q, Zhang XH, Tu YY, Jin ML, Zhao GP, Yu L, Jing NH, Li BM (2006) SNAP-25 in hippocampal CA3 region is required for longterm memory formation. Biochem Biophys Res Commun 347:955-962.

Jope RS (2003) Lithium and GSK-3: one inhibitor, two inhibitory actions, multiple outcomes. Trends Pharmacol Sci 24:441-443.

Kaech S, Banker G (2006) Culturing hippocampal neurons. Nature Protocols 1:2406-2415.

Kelly A, Lynch MA (2000) Long-term potentiation in dentate gyrus of the rat is inhibited by the phosphoinositide 3-kinase inhibitor, wortmannin. Neuropharmacology 39:643-651.

Larson J, Lynch G, Games D, Seubert P (1999) Alterations in synaptic transmission and long term potentiation in hippocampal slices from young and aged PDAPP mice. Brain Res 840:23-35.

Lee VM, Balin BJ, Otvos Jr L, Trojanowski JQ (1991) A68: a major subunit of paired helical filaments and derivatized forms of normal Tau. Science 251:675-678.

Liu SJ, Zhang AH, Li HL, Wang Q, Deng HM, Netzer WJ, Xu H, Wang JZ (2003) Overactivation of glycogen synthase kinase-3 by inhibition of phosphoinositol-3 kinase and protein kinase $\mathrm{C}$ leads to hyperphosphorylation of tau and impairment of spatial memory. J Neurochem 87:1333-1344.

Liu SJ, Zhang JY, Li HL, Fang ZY, Wang Q, Deng HM, Gong CX, GrundkeIqbal I, Iqbal K, Wang JZ (2004) Tau becomes a more favorable substrate for GSK-3 when it is prephosphorylated by PKA in rat brain. J Biol Chem 279:50078-50088.

Lucas FR, Salinas PC (1997) WNT-7a induces axonal remodeling and increases synapsin I levels in cerebellar neurons. Dev Biol 192:31-44.

Lucas FR, Goold RG, Gordon-Weeks PR, Salinas PC (1998) Inhibition of GSK-3beta leading to the loss of phosphorylated MAP-1B is an early event in axonal remodelling induced by WNT-7a or lithium. J Cell Sci 111:1351-1361.

Luscher C, Malenka RC, Nicoll RA (1998) Monitoring glutamate release during LTP with glial transporter currents. Neuron 21:435-441.

Lynch MA, Errington ML, Clements MP, Bliss TV, Redini-Del Negro C, Laroche S (1990) Increases in glutamate release and phosphoinositide metabolism associated with long-term potentiation and classical conditioning. Prog Brain Res 83:251-256.

Marr D (1971) A theory of archicortical function. Proc R Soc Lond B Biol Sci 262:23-81.

Martin SJ, Grimwood PD, Morris RG (2000) Synaptic plasticity and memory: an evaluation of the hypothesis. Annu Rev Neurosci 23:649-711.

Mazarati AM, Hohmann JG, Bacon A, Liu H, Sankar R, Steiner RA, Wynick D, Wasterlain CG (2000) Modulation of hippocampal excitability and seizures by galanin. J Neurosci 20:6276-6281.

McGahon B, Lynch MA (1996) The synergism between metabotropic glutamate receptor activation and arachidonic acid on glutamate release is occluded by induction of long-term potentiation in the dentate gyrus. Neuroscience 72:847-855.

Meberg PJ, Miller MW (2003) Culturing hippocampal and cortical neurons. Methods Cell Biol 71:111-127.

Melloni Jr RH, Hemmendinger LM, Hamos JE, DeGennaro LJ (1993) Synapsin I gene expression in the adult rat brain with comparative analysis of mRNA and protein in the hippocampus. J Comp Neurol 327:507-520.

Morris RGM, Mcnaughton BL (1987) Memory storage in a distributed model of hippocampal formation. Trends Neurosci 10:408-414.

Nichols RA, Chilcote TJ, Czernik AJ, Greengard P (1992) Synapsin I regulates glutamate release from rat brain synaptosomes. J Neurochem 58:783-785.

Ordronneau P, Abdullah LH, Petrusz P (1991) An efficient enzyme immunoassay for glutamate using glutaraldehyde coupling of the hapten to microtiter plates. J Immunol Methods 142:169-176.

Paxinos G, Watson C. (1998) The rat brain in stereotaxic coordinates. San Diego: Academic.

Peineau S, Taghibiglou C, Bradley C, Wong TP, Liu L, Lu J, Lo E, Wu D, Saule E, Bouschet T, Matthews P, Isaac JT, Bortolotto ZA, Wang YT, Collingridge GL (2007) LTP inhibits LTD in the hippocampus via regulation of GSK3 $\beta$. Neuron 53:703-717.

Pei JJ, Tananka T, Tung YC, Braak E, Iqbal K, Grundke-Iqbal I (1997) Distribution, levels, and activity of glycogen synthase-3 in the Alzheimer's disease brain. J Neuropathol Exp Neurol 56:70-78. 
Pieribone VA, Shupliakov O, Brodin L, Hilfiker-Rothenfluh S, Czernik AJ, Greengard P (1995) Distinct pools of synaptic vesicles in neurotransmitter release. Nature 375:493-497.

Plattner F, Angelo M, Giese KP (2006) The roles of cyclin-dependent kinase 5 and glycogen synthase kinase 3 in tau hyperphosphorylation. J Biol Chem 281:25457-25465.

Rabenstein RL, Addy NA, Caldarone BJ, Asaka Y, Gruenbaum LM, Peters LL, Gilligan DM, Fitzsimonds RM, Picciotto MR (2005) Impaired synaptic plasticity and learning in mice lacking beta-adducin, an actin-regulating protein. J Neurosci 25:2138-2145.

Ramsden M, Kotilinek L, Forster C, Paulson J, McGowan E, SantaCruz K, Guimaraes A, Yue M, Lewis J, Carlson G, Hutton M, Ashe KH (2005) Age-dependent neurofibrillary tangle formation, neuron loss, and memory impairment in a mouse model of human tauopathy (P301L). J Neurosci 25:10637-10647.

Reisberg B, Doody R, Stoffler A, Schmitt F, Ferris S, Mobius HJ (2003) Memantine in moderate-to-severe Alzheimer's disease. N Engl J Med 348:1333-1341.

Richter-Levin G, Segal M (1991) The effects of serotonin depletion and raphe grafts on hippocampal electrophysiology and behavior. J Neurosci 11:1585-1596.

Rockenstein E, Torrance M, Adame A, Mante M, Bar-on P, Rose JB, Crews L, Masliah E (2007) Neuroprotective effects of regulators of the glycogen synthase kinase- $3 \beta$ signaling pathway in a transgenic model of Alzheimer's disease are associated with reduced amyloid precursor protein phosphorylation. J Neurosci 27:1981-1991.

Rosahl TW, Spillane D, Missler M, Herz J, Selig DK, Wolff JR, Hammer RE, Malenka RC, Sudhof TC (1995) Essential functions of synapsin I and II in synaptic vesicle regulation. Nature 375:488-493.
Salinas PC, Hall AC (1999) Lithium and synaptic plasticity. Bipolar Disord $1: 87-90$.

Sato K, Morimoto K, Suemaru S, Sato T, Yamada N (2000) Increased synapsin I immunoreactivity during long-term potentiation in rat hippocampus. Brain Res $872: 219-222$.

Scarpini E, Scheltens P, Feldman H (2003) Treatment of Alzheimer's disease: current status and new perspectives. Lancet Neurol 2:539-547.

Shirasaka Y, Wasterlain CG (1994) Chronic epileptogenicity following focal status epilepticus. Brain Res 655:33-44.

Son H, Yu IT, Hwang SJ, Kim JS, Lee SH, Lee YS, Kaang BK (2003) Lithium enhances long-term potentiation independently of hippocampal neurogenesis in the rat dentate gyrus. J Neurochem 85:872-881.

Terada S, Tsujimoto T, Takei Y, Takahashi T, Hirokawa N (1999) Impairment of inhibitory synaptic transmission in mice lacking synapsin I. J Cell Biol 145:1039-1048.

Teter B, Ashford JW (2002) Neuroplasticity in Alzheimer's disease. J Neurosci Res 70:402-437.

Treves A, Rolls ET (1994) Computational analysis of the role of the hippocampus in memory. Hippocampus 4:374-391.

Veliskova J, Velisek L (2007) Beta-estradiol increases dentate gyrus inhibition in female rats via augmentation of hilar neuropeptide Y. J Neurosci 27:6054-6063.

Walling SG, Nutt DJ, Lalies MD, Harley CW (2004) Orexin-A infusion in the locus ceruleus triggers norepinephrine $(\mathrm{NE})$ release and NE-induced long-term potentiation in the dentate gyrus. J Neurosci 24:7421-7426.

Wang ZF, Li HL, Li XC, Zhang Q, Tian Q, Wang Q, Xu H, Wang JZ (2006) Effects of endogenous beta-amyloid overproduction on tau phosphorylation in cell culture. J Neurochem 98:1167-1175. 